
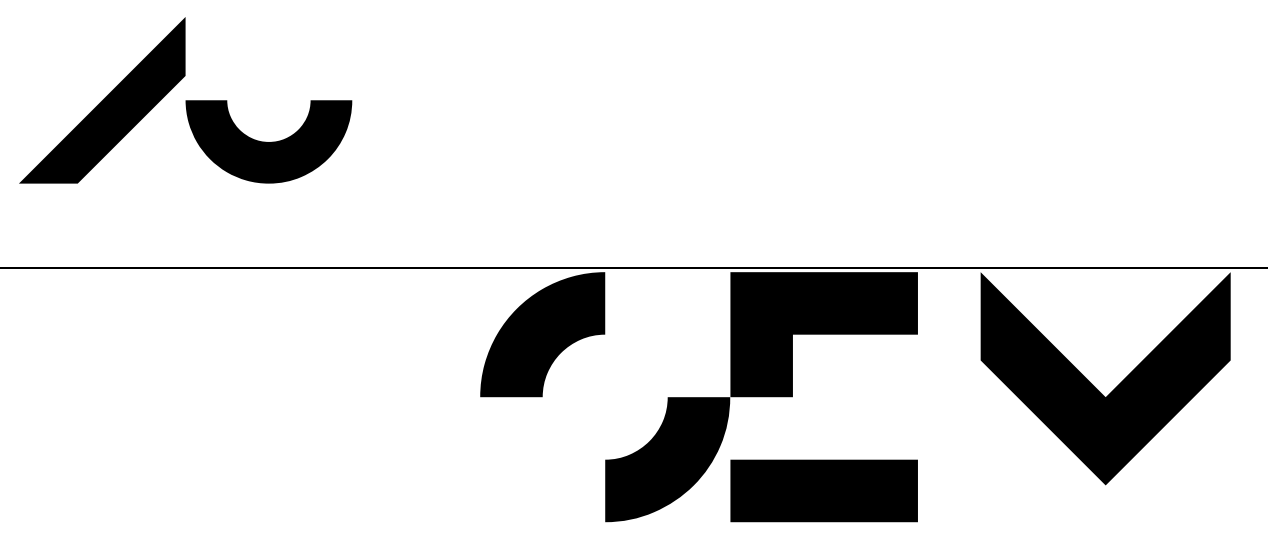

Economics Working Paper

2009-5

\title{
The welfare state and Baumol's law
}

\author{
Martin Paldam
}

School of Economics and Management

Aarhus University

Bartholins Allé 10, Building 1322

DK-8000 Aarhus C - Denmark

Phone +458942 1610

Mail: oekonomi@econ.au.dk

Web: www.econ.au.dk 


\title{
The welfare state and Baumol's law
}

\author{
Martin Paldam, School of Economics and Management, Aarhus University ${ }^{1}$
}

\begin{abstract}
:
The paper considers a two-sector economy with a constant population: The public sector, with stable productivity, and a private sector, with productivity growth. Baumol's law says that such an economy has no steady state. It is demonstrated what this means. Two attempts to uphold a policy that fixes a key ratio are discussed: One policy fixes the tax share - this causes the share of the real public sector to vanish. The other policy fixes the share of real public production - this causes the tax pressure to keep rising.

Jel: $\quad$ H5, H11, O41
\end{abstract}

Keywords: Welfare state, steady state growth

\begin{tabular}{clc}
\hline Section & Content & Page \\
1 & Introduction & 2 \\
2 & The basic Baumol world & 3 \\
3 & Proving Baumol's law & 4 \\
4 & Wages and prices & 6 \\
5 & Policy 1: A constant tax share, i.e., fixing current shares & 8 \\
6 & Policy 2: A constant wefare state, i.e., fixing real shares & 10 \\
7 & The transfers sector: normal case and bureaucratic capture & 13 \\
8 & Discussion: Myopia, good and bad luck & 15 \\
& References & 16 \\
\hline
\end{tabular}

1. Building 1322, Bartholins Allé 10, DK-8000 Aarhus C, Denmark, Phone: +45-8942-1507.

E-mail: mpaldam@econ.au.dk. URL: http://www.martin.paldam.dk. 


\section{Introduction}

Baumol's law says that a two-sector economy with a permanent difference in productivity growth has no steady state. ${ }^{2}$ That is, a Baumol-problem will always emerge. The way it emerges depends on the policy pursued - the paper looks at two policies. Section 2 presents a simple two sector model with a public sector and a private sector, which has faster productivity growth. To study the resulting problems the model is made so that it would be in a perfect steady state, without the difference in productivity growth.

To rule out other problems the analysis makes five assumptions: (a1) The population $(N+L)$ is constant, and so is the working population $(L)$ and the pensioners $(N)$. Thus, the transfer burden $n=N / L$ is constant. (a2) The country has a fine tax system, whith no effects on incentives before the tax pressure hits some limit. It is shown as $65 \%$ on Figure 2. What happens, when it is exceeded, is not analysed. (a3) The budget and (a4) the foreign balances are both zero: There is no debt, and the rest of the world can be disregarded. (a5) The share of investment is constant, proportionally allocated to the sectors, and productivity rises are Harrod neutral. Thus capital can be disregard.

Sections 2-4 define this economy and go through the productivity and inflation dynamics. It is not difficult, but a bit cumbersome. Parts of the analysis are done assuming that wages grow at a constant rate. In the graphical illustrations this rate is set at $2 \%$ p.a.

The government has made a promise that the status quo is preserved, i.e., it promises to tie the economy to a path that is near to a steady state. The promise is made explicit by either of two policies: (1) The tax share will be constant. (2) The welfare state will be preserved. How the Baumol-problem appears under the two policies is discussed in sections 5 and 6. Section 7 discusses the share of transfers, which has been assumed constant till then. The conclusion in section 8 looks at the political economy of an economy having the Baumol problem, and, very briefly, at of the consequences of relaxing some of the assumptions.

2. Paldam (2007) is an earlier version of this paper. See also Paldam and Zeuthen (1988) for long-run comparisons of shares of the public Danish public sector in fixed and current prices, demonstrating that the Baumol effects are substantial in the longer run. The non-existence of a steady state for a two sector economy with different productivity growth rates is a general result. In the classical two sector model of development the traditional sector has low productivity growth and the modern sector has high productivity growth. Development causes the modern sector to absorb the traditional sector, till it is gone. 


\section{The basic Baumol world}

A basic two-sector model with the desired properties is given in Table 1. Public sector productivity is set at 1 , the numeraire of the model. ${ }^{3}$ The private sector productivity grows as an index $w_{t}$ (where $w_{0}=1$ ), which gives the wage rises, throughout the economy, as well. As wages and productivity in the private sector are the same, it generates no inflation. However, the public sector has the same wage rises and no productivity rises; the difference is the inflation of the model. ${ }^{4}$

As the public budget is balanced, taxes are the sum of transfers and public production, $\tau_{t}=$ $\lambda+x_{o t}$, which is equation (8). Till section 7 the share of transfers $\lambda_{t}=\lambda$ is assumed constant. The $x$-curve and the $y$-curve on the graphs are the shares of the current and real share of the public sector, respectively. The two policies discussed in sections 6 and 7 are shown to imply fixing either the $\mathrm{x}$ - or the $\mathrm{y}$-curve to be horizontal.

Table. Basic bookkeeping relations.

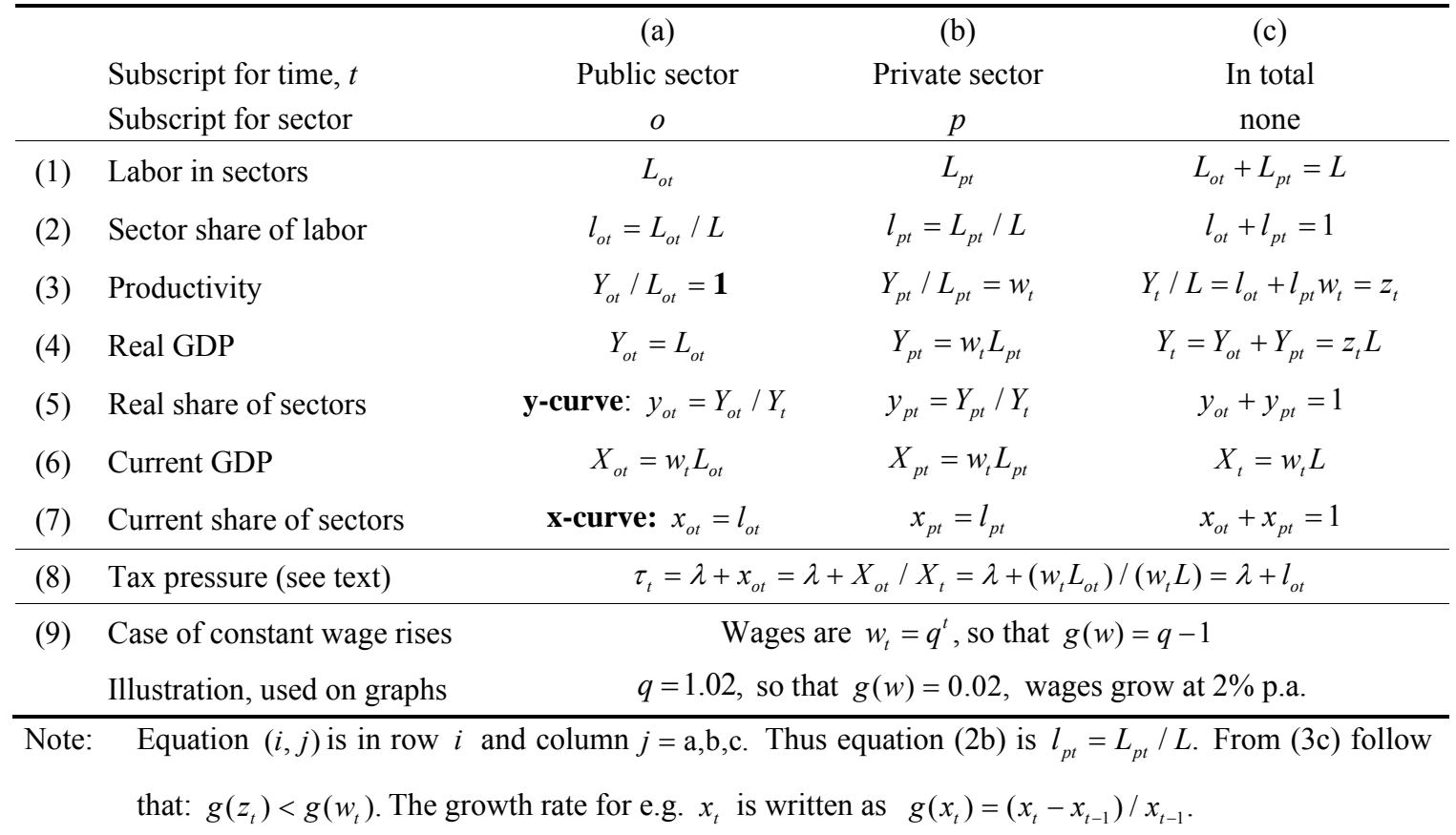

3. The model deals with permanent productivity differences. It is easy to think that public sector productivity is constant, but it might grow as well. In this case the private sector productivity grows is the excess growth.

4. The inflation included is due to relative price changes, which have to be included. Inflation from other sources that hits both sectors proportionally can be added with no effect on the results. 


\section{Proving Baumol's law}

First, $(2 \mathrm{c}) l_{o t}+l_{p t}=1$, is used to eliminate $l_{o t}$ from the productivity equation: $z_{t}=l_{o t}+w_{t} l_{p t}=1-l_{p t}+w_{t} l_{p t}=1+\left(w_{t}-1\right) l_{p t}$. From this we calculate

$$
g\left(z_{t}\right)=\frac{z_{t}-z_{t-1}}{z_{t-1}}=\frac{\left(1+\left(w_{t}-1\right) l_{p t}\right)-\left(1+\left(w_{t-1}-1\right) l_{p t-1}\right.}{1+\left(w_{t-1}-1\right) l_{p t-1}}=\frac{\left(w_{t}-1\right) l_{p t}-\left(w_{t-1}-1\right) l_{p t-1}}{1+\left(w_{t-1}-1\right) l_{p t-1}}
$$

After divisison with $w_{t-1},(10)$ becomes: $g\left(z_{t}\right)=\frac{\left(\frac{w_{t}}{w_{t-1}}-\frac{1}{w_{t-1}}\right) l_{p t}-\left(1-\frac{1}{w_{t-1}}\right) l_{p t-1}}{\frac{1}{w_{t-1}}+\left(1-\frac{1}{w_{t-1}}\right) l_{p t-1}}$

For $t \rightarrow \infty, w_{t} \rightarrow \infty$, so $\frac{1}{w_{t-1}} \rightarrow 0 .{ }^{5}$ Thus: $g\left(z_{t}\right) \rightarrow \frac{\frac{w_{t}}{w_{t-1}} l_{p t}-l_{p t-1}}{l_{p t-1}}=\frac{w_{t}}{w_{t-1}} \frac{l_{p t}}{l_{p t-1}}-1$

This can only be constant if $\frac{w_{t}}{w_{t-1}}=\frac{l_{p t-1}}{l_{p t}}$.

As $w_{t}$ is rising, $l_{p t}$ must be falling. For the two-sector model above to have a steady state, it should have constant factor shares. Hence, there is no steady state. This proves Baumol's law.

Formally, the fall ceases when $l_{p t}$ is zero, but then there is no private sector. That is, $l_{p t} \rightarrow 1$, so that also $l_{o t-1} / l_{o t} \rightarrow 1$. Thus, $z_{t} \rightarrow 1$ throughout the economy.

An alternative possibility is that $l_{p t}$ goes to 1 , so that $z_{t}=w_{t}$ already in equation ( $3 \mathrm{a}$ ) and then most of the calculation becomes impossible. The model is in steady state from the start.

Hence, even when $g\left(z_{t}\right)<g\left(w_{t}\right)$, for all $t$, it also holds that $g\left(z_{t}\right) \rightarrow g\left(w_{t}\right)$, for $t \rightarrow \infty$.

In the case of constant wage rises: $w_{t}=q^{t}$, this is:

$$
g\left(z_{t}\right)=\frac{\left(q^{t}-1\right) l_{p t}-\left(q^{t-1}-1\right) l_{p t-1}}{1+\left(q^{t-1}-1\right) l_{p t-1}}
$$

5. Assuming that $w_{t} / w_{t-1}$ stays finite. 
As $q$ is an index with base year 1 , (i.e. for $t=1, q^{1-1}=1$ ), so $g\left(z_{1}\right)$ becomes

(12) $\quad g\left(z_{1}\right)=\frac{(q-1) l_{p t}-(1-1) l_{p t-1}}{1+(1-1) l_{p t-1}}=(q-1) l_{p 1}=g(w) l_{p 1}$

$g\left(z_{t}\right)$ is thus a function that starts at $g(w) l_{p 1}$ for $t=0$ and rises to $g(w)$ as $t \rightarrow \infty$. 


\section{Wages and prices}

In the model, inflation is the difference between wage and productivity rises (from (10)):

$$
\pi_{t}=g\left(w_{t}\right)-g\left(z_{t}\right)=\frac{w_{t}-w_{t-1}}{w_{t-1}}-\frac{\left(w_{t}-1\right) l_{p t}-\left(w_{p t-1}-1\right) l_{p t-1}}{1+\left(w_{t-1}-1\right) l_{p t-1}}=\frac{\text { nominator }}{\text { denominator }}
$$

Nominator: $\left[\left(w_{t}-w_{t-1}\right)\left(1+\left(w_{t-1}-1\right) l_{p t-1}\right)\right]-\left[w_{t-1}\left(\left(w_{t}-1\right) l_{p t}-\left(w_{t-1}-1\right) l_{p t-1}\right)\right]=$

$$
\begin{aligned}
& w_{t}+w_{t} w_{t-1} l_{p t-1}-w_{t} l_{p t-1}-w_{t-1}-w_{t-1}^{2} l_{p t-1}+w_{t-1} l_{p t-1}-w_{t-1} w_{t} l_{p t}+w_{t-1} l_{p t}+w_{t-1}^{2} l_{p t-1}-w_{t-1} l_{p t-1}= \\
& w_{t}-w_{t-1}-w_{t} w_{t-1} l_{p t}+w_{t} w_{t-1} l_{p t-1}+w_{t-1} l_{p t}-w_{t} l_{p t-1}= \\
& \left(w_{t}-w_{t-1}\right)-w_{t} w_{t-1}\left(l_{p t}+l_{p t-1}\right)+w_{t-1} l_{p t}-w_{t} l_{p t-1}
\end{aligned}
$$

Denominator: $w_{t-1}\left[1+\left(w_{t-1}-1\right) l_{p t-1}\right]$

So the full expression for inflation is:

$$
\pi_{t}=\frac{\left(w_{t}-w_{t-1}\right)-w_{t} w_{t-1}\left(l_{p t}+l_{p t-1}\right)+w_{t-1} l_{p t}-w_{t} l_{p t-1}}{w_{t-1}\left[1+\left(w_{t-1}-1\right) l_{p t-1}\right]}
$$

In the long run, the nominator goes to zero and the denominator to infinity. This is easy to see by noting that $l_{p t} \rightarrow 1$, and inserting $l_{p t}=l_{p t-1}=1$, which reduces (13b) to:

$\pi_{t} \rightarrow \frac{\left(w_{t}-w_{t-1}\right)-w_{t} w_{t-1}(1-1)-\left(w_{t}-w_{t-1}\right)}{w_{t-1}\left[1-w_{t-1}-1\right]}=\frac{0}{w_{t-1}^{2}}=0$. This was already derived in Section 3

In the case where $w_{t}=q^{t}$, (13b) becomes:

$$
\pi_{t}=\frac{\left(q^{t}-q^{t-1}\right)-q^{2 t-1}\left(l_{p t}-l_{p t-1}\right)-\left(q^{t} l_{p t-1}-q^{t-1} l_{p t}\right)}{q^{t-1}\left[1+\left(q^{t-1}-1\right) l_{p t-1}\right]}, \text { which after division in nominator }
$$

and denominator by $q^{t-1}$ becomes:

$$
\frac{(q-1)-q^{t}\left(l_{p t}-l_{p t-1}\right)-\left(q l_{p t-1}-l_{p t}\right)}{1+\left(q^{t-1}-1\right) l_{p t-1}}=\frac{(q-1)-\left(q^{t}-1\right) l_{p t}+\left(q^{t}-q\right) l_{p t-1}}{1+\left(q^{t-1}-1\right) l_{p t-1}}
$$


Equation (14) can be checked by inserting $t=1$ :

$$
\pi_{1}=\frac{(q-1)-(q-1) l_{p t}+(q-q) l_{p t-1}}{1+(1-1) l_{p t-1}}=(q-1)\left(1-l_{p t}\right)=g(w)\left(1-l_{p t}\right)=g(w) l_{o t}
$$

This tallies perfectly with (12).

Even when the expressions for productivity and inflation look a bit cumbersome, they are simple and make perfect sense at the two margins. Also, the paths of the variables between the two margins are smooth monotonous curves, which are easy to calculate when realistic values for the starting point and the parameters are chosen.

This will be shown in the policy experiments. To allow the calculations of the paths, the experiments look at the case of constant private sector productivity and hence wage growth, i.e., $w_{t}=q^{t}$, where the illustrations on Figures 1 and 2 assume that $g(q)=0.02$. 


\section{Policy 1: A constant tax share, i.e., fixing current shares}

This policy promises that the tax share is fixed. Since the tax share is the sum of the shares of current public production and transfers, a fixed tax share amounts to fixing the two current shares $\lambda$ and $x_{o t}$, so the $\mathrm{x}$-curve and the $\lambda$-curve are both horizontal (and chosen to be the same). Shifts between the two current public shares are briefly discussed in Section 7 . Equation (8) says that this means that $l_{o t}=l_{o}$ is constant, and, consequently, so is $l_{p t}=l_{p}$. It follows that: $L_{p t}=L_{p}$ and $L_{o t}=L_{o}$.

From equation (4a) $Y_{o t}=L_{o}$, so $Y_{o t}=Y_{o}$. The constant labor forces mean that (5a) gives:

$$
y_{o t}=\frac{Y_{o}}{Y_{t}}=\frac{L_{o}}{L_{p} z_{p t}}=\frac{L_{o}}{L_{p}} z_{t}^{-1}=\frac{L_{o}}{L_{p}} q^{-t}
$$

Thus, the y-curve (the share of the public sector in real production) falls constantly. From the definition of inflation (13a) this causes inflation to fall gradually to zero.

Figure 1. The path of the public sector with a constant tax pressure, i.e., a constant share of current public.production: The x-curve is horizontal

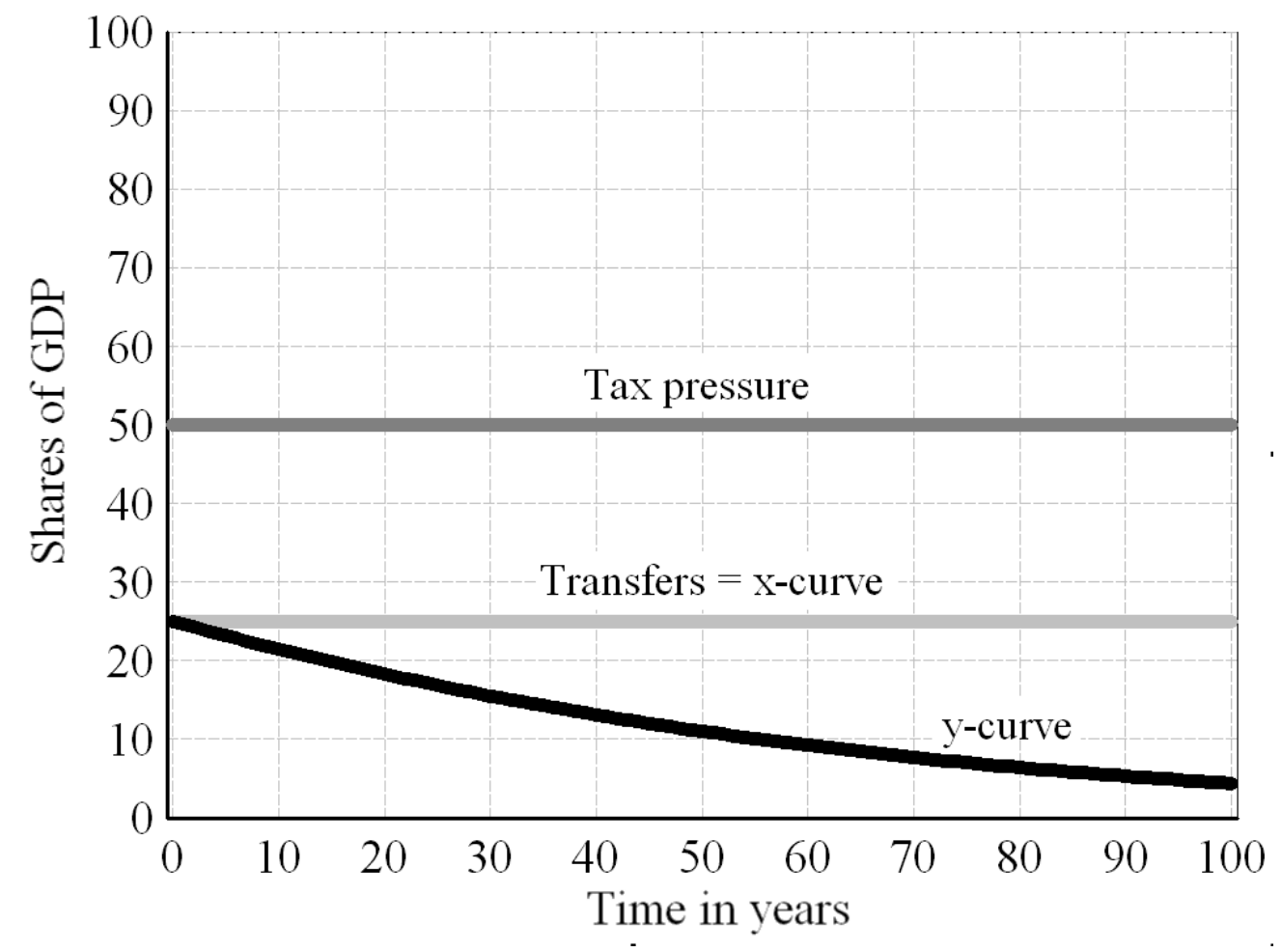


What this version of a "constant" welfare state implies can be shown by a simple graph, where $g(q)=0.02$. The paths of the variables starts in a situation where, $y_{o 0}=x_{o 0}=25 \%=\lambda$. That is, the shares of public production and transfers are both $25 \%$ of GDP. ${ }^{6}$ This choice is made in order not to burden the graph with too many lines, but it is - of course - just a choice. By (8) the two choices mean that the fixed tax pressure is 50\%. Figure 1 shows the path of the relevant shares.

What does this mean? Let us imagine that the public sector is same number of teachers teaching the same number of children (constant as is the labor force) the same number of classes, etc. Then surely things are in balance. However, in order to be more productive, when the pupils leave the school, it must teach them better. That is, there must be productivity rises. If there are no productivity rises a problem occurs

6. The choices of the two shares are made to make the situation look a bit like the Danish in the first decade of the $21^{\text {st }}$ century. 


\section{6. $\quad$ Policy 2: A constant welfare state, i.e., fixing real shares}

This policy is a promise that the welfare state should be preserved in real terms. Consequently, the policy sets $y_{o t}=y_{o}=y_{p} / \mu$ constant (that is the y-curve is horizontal), so that also $y_{p t}=y_{p}=\left(1-y_{o}\right)=\mu y_{o}$ is constant, $\mu$ is the factor of proportionality: $\mu=y_{p} / y_{o}$.

As $y_{o}=\frac{Y_{o t}}{Y_{t}}=\frac{L_{o t}}{L_{o t}+L_{p t} w_{t}}=\frac{L_{o t}}{L_{o t}+L_{p t} q_{t}}$ this means $y_{o}\left(L_{o t}+q^{t} L_{p t}\right)=L_{o t}$, or $y_{o}\left(l_{o t}+q^{t} l_{p t}\right)=l_{o t}$

or $y_{o}\left(l_{o t}+q^{t}\left(1-l_{o t}\right)=l_{o t}\right.$ so that: $q^{t} y_{o}=\left(y_{p}+q^{t} y_{o}\right) l_{o t}$ and

$$
l_{o t}=\frac{q^{t} y_{o}}{y_{p}+q^{t} y_{o}}=\frac{1}{1+\mu q^{-t}}
$$

Figure 2. The path of the public sector when the welfare state is preserved

i.e., a constant share of real public production: The y-curve is horizontal

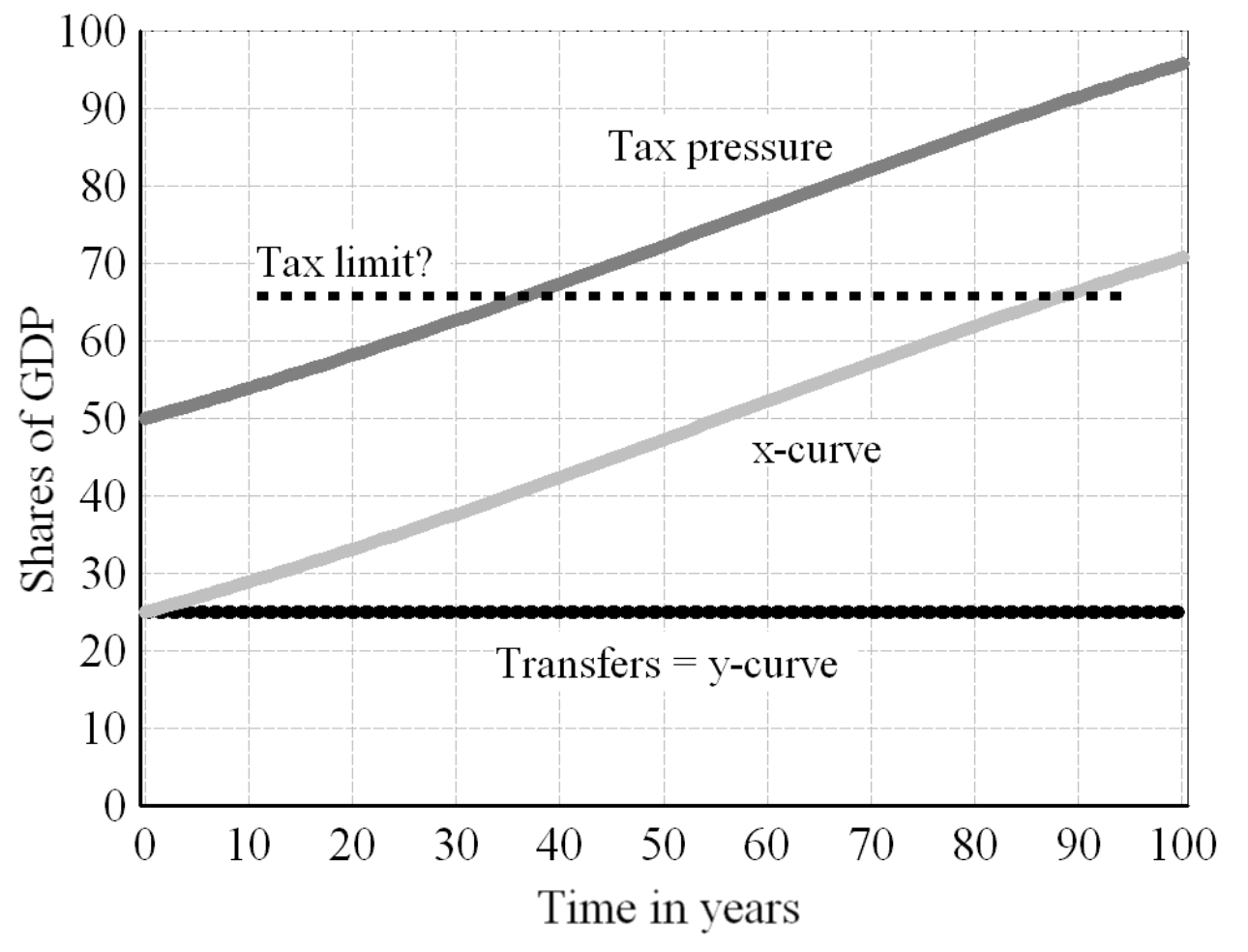


As the denominator gets smaller and smaller, this indicates a steadily increasing labor share $l_{o t}$ for the public sector. This causes the current share of the public sector - the x-curve - and public employment to rise all the time.

Figure 2 - starting from the same proportions as figure 1 - shows what happens. This time the $y$-curve is horizontal and the $\mathrm{x}$-curve goes up. The private sector share that is the distance between the $\mathrm{x}$-curve and $100 \%$ is squeezed.

This process cannot continue, but must stop at some limit (drawn at $65 \%$ ). It is interesting to speculate about the location of this limit, but this is outside the model discussed.

The model also provides an inflation rate:

(18a) $\pi_{t}=\frac{\left(q^{t}-1\right) l_{o t}-\left(q^{t}-q\right) l_{o t-1}}{q^{t-1}-\left(q^{t-1}-1\right) l_{o t-1}}$. If $l_{o t}=\frac{1}{1+\mu q^{-t}}$ and $l_{o t-1}=\frac{1}{1+\mu q^{-t+1}}$ is inserted, it is:

$$
\pi_{t}=\frac{\frac{q^{t}-1}{1+\mu q^{-t}}-\frac{q^{t}-q}{1+\mu q^{-t+1}}}{q^{t-1}-\frac{q^{t-1}-1}{1+\mu q^{-t+1}}}=\frac{\left(q^{t}-1\right)\left(1+\mu q^{-t+1}\right)-\left(q^{t}-q\right)\left(1+\mu q^{-t}\right)}{q^{t-1}\left(1+\mu q^{-t+1}\right)\left(1+\mu q^{-t}\right)-\left(q^{t-1}-1\right)\left(1+\mu q^{-t+1}\right)}=\frac{\text { nominator }}{\text { denominator }} .
$$

The nominator is:

$$
\begin{aligned}
& \left(q^{t}-1\right)\left(1+\mu q^{-t+1}\right)-\left(q^{t}-q\right)\left(1+\mu q^{-t}\right)=q^{t}-1+q \mu-q^{-t+1} \mu+q^{t}+q-\mu+q^{-t+1} \mu= \\
& q-1+q \mu-\mu=(q-1)(1+\mu)
\end{aligned}
$$

The denominator is:

$$
\begin{aligned}
& q^{t-1}\left(1+\mu q^{-t+1}\right)\left(1+\mu q^{-t}\right)-\left(q^{t-1}-1\right)\left(1+\mu q^{-t+1}\right)= \\
& \left(q^{t-1}+\mu+\left(q^{t-1}+\mu\right) \mu q^{-t}\right)-\left(q^{t-1}+\mu+\left(q^{t-1}-1\right) \mu q^{-t+1}\right)=\mu q^{-t}+\mu^{2} q^{-t}+1+\mu q^{-t+1}= \\
& \mu q^{-1}\left(1+\mu q^{-t+1}\right)+\left(1+\mu q^{-t+1}\right)=\left(1+\mu q^{-1}\right)\left(1+\mu q^{-t+1}\right)
\end{aligned}
$$

So the rate of inflation becomes:

$$
\pi_{t}=\frac{(q-1)(1+\mu)}{\left(1+\mu q^{-1}\right)\left(1+\mu q^{-t+1}\right)}=g(q)\left\{\frac{1+\mu}{1+\mu q^{-1}}\right\} \frac{1}{1+\mu q^{-t+1}}
$$


For $t \rightarrow \infty$ it becomes $\pi_{t} \rightarrow g(q)\left\{\frac{1+\mu}{1+\mu q^{-1}}\right\} \approx g(q)$

The interpretation of the small adjustment term in the \{\} -bracket becomes clear if the same derivation is done using the prices of the end period in the denominator:

$$
\hat{\pi}_{t}=\frac{\left(q^{t}-1\right) l_{o t}-\left(q^{t}-q\right) l_{o t-1}}{q_{t}-\left(q^{t}-1\right) l_{o t}}=g(q) \frac{1}{1+\mu q^{-t+1}} \rightarrow g(q) \text { for } t \rightarrow \infty
$$

Inflation converges to the growth rate of wages, as it must, when the real public sector comes to dominate. 


\section{The transfers sector: Normal case and bureaucratic capture}

Till now the analysis has assumed that the share of transfers is constant. The working population, $L$, is constant, and so is the number of transfer recipients, $N$. Consequently, the ratio $N / L=n$ is fixed too. Assume that $n \approx 0.5 .^{7}$ Aggregate transfer payments are defined as, $\Lambda_{t}=v_{t} N$, where $v_{t}$ is the public pension rate.

The transfer implication of both Policy 1 and Policy 2 is: $v_{t}=\theta w_{t}$. That is, it is assumed to be a constant fraction of the wage rate. Consequently, the share of transfers is:

$$
\lambda_{t}=\frac{\Lambda_{t}}{X_{t}}=\frac{v_{t}}{w_{t}} \frac{N}{L}=\theta n . \text { It is constant and implies: } \theta=\lambda / n
$$

Hence, the $\lambda$-curve is horizontal (both in current and real prices), as drawn on Figures 1 and 2 , if $\theta=\lambda / n$. If realistic orders of magnitude, such as $\lambda \approx 0.25$ and $\mathrm{n} \approx 0.5$, are inserted in equation (20), it gives $\theta \approx 0.5$. As $\lambda$ is a linear function of $\theta$, with a slope of $1 / n \approx 2, \lambda$ is quite sensitive to $\theta$. The analysis of Policy 1 and 2 in sections 5 and 6 thus assume that a fixed $\theta$ is chosen - then everything is as discussed. This completes the normal case.

However, as Policy 2 leads to a pressure on the tax limit, something has to give in. Assume that Policy 2 is captured by the bureaucracy, which reinterprets it to mean that the raise of current share of public production increases, $y_{o t}$, should be fixed as long as possible. That is, the x-curve from Figure 2 becomes the fixed public policy. From Figure 2 it can be seen how the private sector is squeezed. With bureaucratic capture transfers are squeezed as well, to get a negatively sloping $\lambda$-curve that reduces the rise of the tax share.

From equation (20) follows that the condition for squeezing the share of transfers is that $\theta_{t}$ is falling, so that pensions fall relatively to wages. Politically this is difficult to accomplice; but it is possible to think of many rules that produce this outcome. The results for the rest of the model are rather easy to imagine, so two cases only will be drawn: (i) an extreme squeeze and (ii) one moderate squeeze.

7. Imagine a perfectly rectangular population pyramid, where people live to 80 , and move out of parental care at the age of 20. That gives a potential labor life of 60 years. If people start to work at 23 and retire at 67 , they are outside the labor force 16 of the 60 years. Natural unemployment, illness, maternity leave etc, adds $10 \%$ of the remaining years 44 years. Thus, people receive pensions 20 of the 60 years. The transfer burden is $n=N / L=$ $20 / 40=0.5$. Assume that the transfers to people above 23 is $60 \%$ of wages, while it is only $20 \%$ for people under 24 , then the average is close to $50 \%$. 
Figure 3. As Figure 2, with squeezed transfers: Two cases

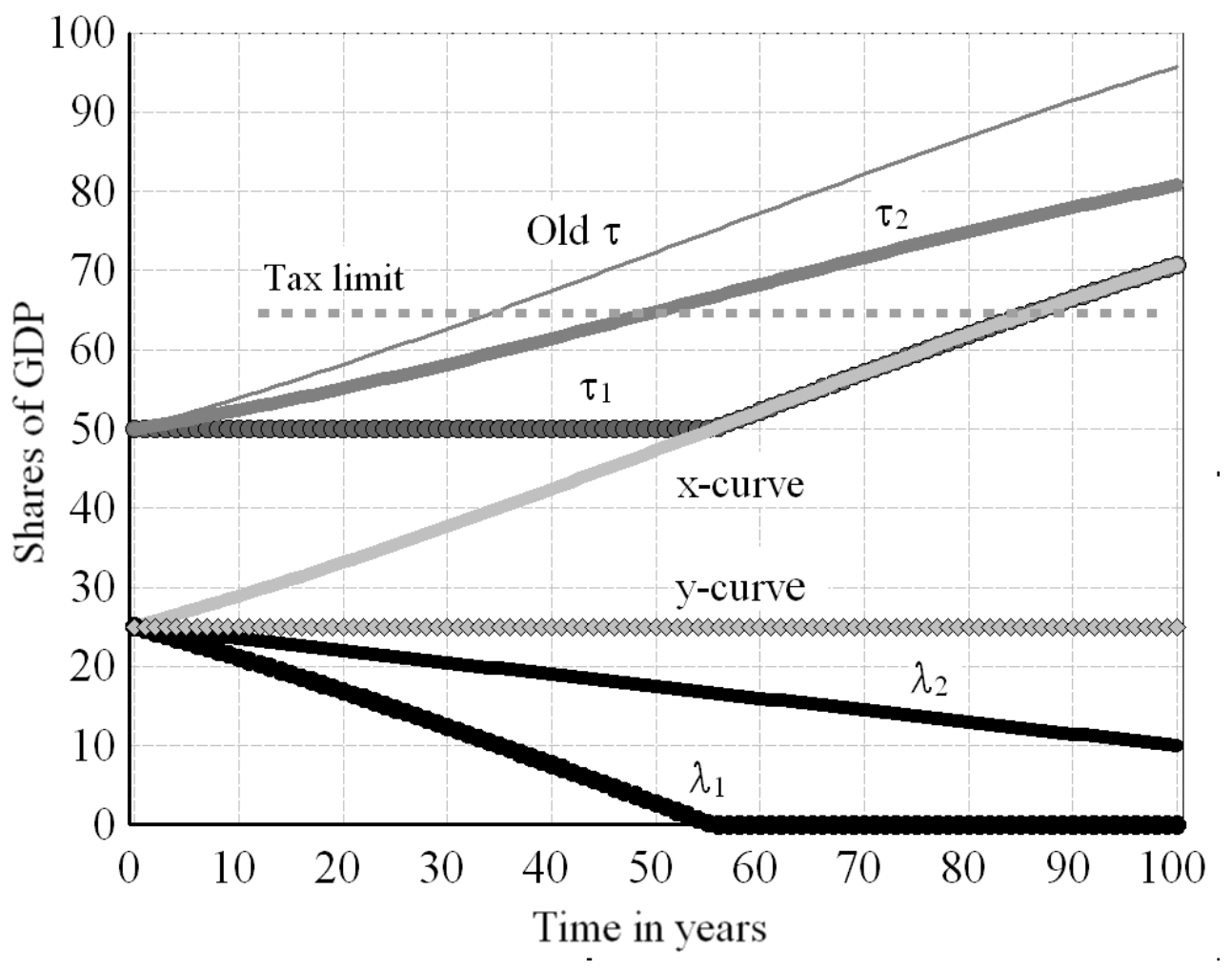

(i) The most radical squeeze is to reduce $\lambda$ corresponding to the rise in $x_{o t}$. On Figure 2 it is drawn as the $\lambda_{1}$-line that permits the tax share $\tau_{1}$ to be horizontal as long as there are still transfers. They are exhausted after 55 years, and then the $\tau_{1}$-curve follows the x-curve. It intersects with the tax-limit after about 85 years.

All moderate squeezes give $\lambda$-curves between the vertical one that follows the $y$-line and the $\lambda_{1}$-line. They give tax share lines between the "Old $\tau$ " (from Figure 2), and the extreme $\tau_{1 t}=\lambda_{1 t}+x_{o t}$ tax pressure drawn as the $\tau_{1}$-curve. One such possibility is:

(ii) The $\lambda_{2}$-line, which gives the tax pressure line $\tau_{2}$. It is linear and falls from $25 \%$ to $10 \%$ over the 100 years. This squeeze delays the intersection with the tax limit by app 10 years.

It is easy to propose various policies that generate falling $\lambda$-paths looking like the $\lambda_{2}$-line. All such paths' have to set the pension $v_{t}$ on a path that rises slower than $w_{t}$. One such policy is to keep the real $v_{t}$ pension rate constant. Here the $\lambda$-line looks as the y-curve on Figure 1. Another possibility is to set the pensions $v_{t}=\theta z_{t}$, which is the rate of productivity rises in the economy. This gives a $\lambda$-line close to $\lambda_{2}$. 


\section{Discussion: Myopia, good and bad luck}

The analysis in the paper deals with a simple two sector model, which is in perfectly balance, if the two sectors grow at the same rate. However, as the public sector has lower productivity growth than the private one, no steady state growth is possible. This is shown in general, and in two policy cases, where the government adopts a policy fixing a major ratio. A Baumolproblem occurs in both policy cases.

The problem is only in the order of $7-10 \%$ of GDP in a 20 -years perspective. Within one election period, it is just $1-2 \%$ of GDP. So, it is small and easy to neglect - also, it is difficult to explain to people and to busy policy makers. One of the most well established results in modern political economy is that political processes enforces myopia on the decision making process. Consequently this theory predicts that Baumol's law is ignored by the political decision process, as is indeed the case. But still, it never stops growing.

The problem can be delayed in several ways: (a) The most obvious is to try to increase productivity in the public sector, i.e., by privatization and outsourcing. (b) It also helps to run a public sector surplus that tilts the tax pressure curve to a lower slope, by increasing taxes now and permitting lower taxes later.

Furthermore, luck in the form of good, but transitory events, may occur. (c) Unemployment may fall below its natural level reducing public expenditures and increasing the tax base. (d) Variations in the population age structure may cause the dependency ratio to fall below its long-run value. (e) Conditions may allow a relative reduction in public sector wages.

When luck runs out the problem returns with a vengeance: (c) Unemployment rises above its natural level; (d) the dependency ration rises above its long run-value; and (e) the public sector wage arrears leads to strikes and compensations.

Consequently, Baumol's law will turn up in one period as one concrete problem and in another period as another problem. It will then be ascribed to the concrete problem. This blurs the underlying "creeping" character of the fundamental Baumol-problem: The welfare state has no steady state. 
Acknowledgement: I am grateful to Laurent Callot for research assistance.

\section{References:}

Baumol, W.J., 1967. Macroeconomics of Unbalanced Growth: An Anatomy of Urban Crisis. American Economic Review 57, 415-26

Baumol, W.J., 1986. Productivity growth, convergence, and welfare: What the long-run data show. American Economic Review 76, 1072-85

Paldam, M., Zeuthen, H.E., 1988. The Expansion of the Public Sector in Denmark - a Post Festum? Cpt. 8 pp 157-186 in Lybeck, J., Henrekson, M., eds., The Expansion of the Public Sectors in the West. NorthHolland, Amsterdam

Paldam, M., 2007. Grænserne mellem den offentlige og private sektor - vil kommunalreformen rykke dem? Samfundsøkonomen december 2006, 16-19 


\section{Economics Working Paper}

2008-08: Torben M. Andersen and Allan Sørensen: Globalisation squeezes the public sector - is it so obvious?

2008-09: Kristin Kleinjans: Do Gender Differences in Preferences for Competition Matter for Occupational Expectations?

2008-10: Martin Paldam: Development and foreign debt: The stylized facts 1970-2006

2008-11: Christian Dahl Winther: Brand popularity, endogenous leadership, and product introduction in industries with word of mouth communication

2008-12: $\quad$ Maria Knoth Humlum: Timing of Family Income, Borrowing Constraints and Child Achievement

2008-13: $\quad$ Erich Gundlach and Martin Paldam: Income and Democracy: A Comment on Acemoglu, Johnson, Robinson, and Yared (2008)

2008-14: Helena Skyt Nielsen, Torben Sørensen and Christopher Taber: Estimating the Effect of Student Aid on College Enrollment: Evidence from a Government Grant Policy Reform

2008-15: $\quad$ Erich Gundlach and Martin Paldam: The Democratic Transition. A study of the causality between income and the Gastil democracy index

2008-16: $\quad$ Alexander K. Koch and Eloïc Peyrache: Aligning Ambition and Incentives

2009-01: $\quad$ Alexander K. Koch, Albrecht Morgenstern and Philippe Raab: Career concerns incentives: An experimental test

2009-02: $\quad$ Maria Knoth Humlum and Rune Majlund Vejlin: The Effects of Financial Aid in High School on Academic and Labor Market Outcomes: A QuasiExperimental Study

2009-03: $\quad$ Philipp J.H. Schröder and Allan Sørensen: Second Thoughts on Exporter Productivity

2009-04: Lene Kromann: Does Employee Body Weight Affect Employers' Behavior?

2009-05: Martin Paldam: The welfare state and Baumol’s law 